\title{
Differences and similarities of biophysical and biological characteristics between GBM and astrocyte cells
}

Berrin Özdil ( $\square$ ozdlberrin@gmail.com )

Ege University Faculty of Medicine: Ege Universitesi Tip Fakultesi https://orcid.org/0000-0001-60812308

\section{Duygu Calik-Kocaturk}

Ismail Fehmi Cumalioglu City Hospital

Cisem Altunayar-Unsalan

Ege Universitesi

\section{Eda Acikgoz}

Van Yuzuncu Yil University: Van Yuzuncu Yil Universitesi

\section{Fatih Oltulu}

Ege University: Ege Universitesi

\section{Volkan Gorgulu}

Ege University Faculty of Medicine: Ege Universitesi Tip Fakultesi

\section{Aysegul Uysal}

Ege University Faculty of Medicine: Ege Universitesi Tip Fakultesi

\section{Gulperi Oktem}

Ege University Faculty of Medicine: Ege Universitesi Tip Fakultesi

\section{Ozan Unsalan}

Ege University: Ege Universitesi

\section{Huseyin Aktug}

Ege University Faculty of Medicine: Ege Universitesi Tip Fakultesi https://orcid.org/0000-0003-41508495

\section{Research Article}

Keywords: Cancer cells, GBM, astrocytes, AFM, SEM/EDS, XPS

Posted Date: November 18th, 2021

DOI: https://doi.org/10.21203/rs.3.rs-1054698/v1 
License: (c) (i) This work is licensed under a Creative Commons Attribution 4.0 International License. Read Full License 


\section{Abstract}

The current cancer studies focus on the molecular-targeting diagnostics and their interaction with surrounding microenvironment, however, there are some missing points on the characterization of the cells with their topological differences and elemental composition. Glioblastoma multiforme (GBM) which is an astrocytic aggressive brain tumour with short survival time. GBM and astrocyte cells may differ at molecular level and the elemental and topological evaluation of these cells are vital for a definition of new potential targets for cancer research. Here, we report the topology and chemistry of cancer (GBM) and healthy (astrocyte) cells by atomic force microscopy (AFM), scanning electron microscopy (SEM) supported with energy dispersive X-ray spectroscopy (EDS) and X-ray photoelectron spectroscopy (XPS), for the first time. Additionally, F-actin Immunofluorescence staining and Real-Time Polymerase chain reaction (RT-PCR) techniques were performed. Actin related genes were similar in level of gene expression; however, F-actin protein intensities were different. The gene expressions related to the invasion were elevated in GBM cells. Morphologically, GBM cells were found to be longer and narrower while astrocytes were shorter and more disseminated based on AFM. Furthermore, roughness values of these cells were relatively close to each other. SEM-EDS analysis demonstrated that elongated GBM cells exhibited several filopodial protrusions whereas the astrocyte surfaces were rougher in lamellipodial area. Our investigation provides considerable further insight into rapid cancer cell characterization field in terms of its combinatorial spectroscopic and microscopic approach.

\section{Introduction}

Astrocytes are the most common cell type of central nervous system (CNS) and have critical functions such as organizing of CNS homeostasis by contribution to the construction of the blood-brain barrier, maintaining appropriate synaptic transmission, contribution to neural development, responding to injuries and diseases (Sofroniew and Vinters 2010; Chaboub and Deneen 2012; Guttenplan and Liddelow 2018). A previous work showed the heterogeneity in number and morphology according to their regions in the brain (Zhou et al. 2019). Astrocytes are in contact with numerous vessels, nerves and synapse regions as a result of their special morphological structures (Oberheim et al. 2009). Thus, to form this unique morphology, astrocytes have an improved cytoskeleton and the most important intermediate filament therein is glial fibrillary acidic protein (GFAP) (Hol and Pekny 2015). Dysregulations in the cytoskeleton of astrocytes contribute to the formation of cancer (Yang et al. 2013).

Glioblastoma multiforme (GBM) also called glioblastoma is classified as grade IV diffuse astrocytic and oligodendroglial tumours by World Health Organization (WHO) (Louis et al. 2016). It is the most common malign primary brain tumour includes $48.3 \%$ of all primary malign brain tumour and $14.6 \%$ of all primary brain tumours. Despite advances in treatment options, GBM patients have a $6.8 \%$ five years postdiagnosis survival (Ostrom et al. 2019). Surgical excision of the entire GBM has difficulties due to the localization of the tumour in the central nervous system and the absence of sharp borders between neoplastic and healthy tissues. Therefore, effective treatment methods for GBM are still limited and much more efforts are inevitable (Lara-Velazquez et al. 2017). 
The concept of cancer biology is associated with the cells which start to behave differently from healthy cells, both morphologically and biochemically, especially the potential for rapid division due to changes in control points of the cell cycle. The loss of control in the G1/S stage of the cell cycle and loss of genetic material within chromosome $10 \mathrm{q}$ leading to PTEN mutation as well as mutation of EGFR, FGFR2, AKT3 genes may play a role in the development of GBM (Urbańska et al. 2014). Particularly, the dysregulation of apoptotic mechanisms is one of the major problems in GBM (Valdes-Rives et al. 2017). It must be pointed out that a better understanding of the regulatory process of apoptosis is needed to develop new diagnostic and therapeutic strategies that lead to the initiation of apoptosis signalling. On the other hand, the cytoskeleton of the cell plays a crucial role not only in maintaining its size and shape but also governing how the cells sense and respond to their environment. Various cellular processes such as cell division, migration, and regulation of gene expression have been linked to the cytoskeleton. In GBM, the hypoxic environment is known to orchestrate changes in cytoskeleton dynamics, thereby promoting these cells to migrate (Velásquez et al. 2019).

Changes in the cytoskeleton affect the motility of the cancer cell by changing the cell surface properties (Arjonen et al. 2011; Hohmann and Dehghani 2019). Cdc42 is one of the most prominent members of Rho-GTPases and with Rho and Rac, these three genes regulate cell morphology, membrane ruffles, filopodia structure and actin reorganization. Cdc42 activity also increases glioma migration and invasion. It was also reported that Cdc42 activity in glioma may increase the number of filopodia (Okura et al. 2016). Rho is another protein family interacting with the actin cytoskeleton, are hence involved in the regulation of the cytoskeleton reorganization. As a downstream effector of Rho, the Rho-associated protein kinase (ROCK1) is a serine-threonine protein kinase. It was shown that when ROCK1 binds to the active GTP-bound form of Rho, it is activated and then interacts with the actin cytoskeleton to promote the formation of stress fibres, as well as focal adhesion. Moreover, ROCK1 has been reported to provide a feedback mechanism and regulate the activity of upstream proteins Rac 1 and RhoA, which act as key regulators in the reorganization of the actin cytoskeleton. Since the reorganization of the actin cytoskeleton plays an active role in cancer cell migration and invasion, ROCK is believed to be involved in the process of cancer invasion and metastasis. In addition, it was reported that ROCK1 modulates cell motility via integrin $\beta 1$-activated FAK signalling (Hu et al. 2019). Rho GTPases have been implicated in a variety of cellular processes and most importantly of cytoskeleton organization and its impact on biological functions on cellular movement and division. Cdc42, Rac1 and RhoA have a modulatory role in cellular trafficking and tumorigenesis. The highly conserved RhoA, RhoB and RhoC proteins are frequently aberrantly expressed in human tumours, with RhoA and RhoC being commonly overexpressed whereas RhoB is often downregulated. RhoA has been implicated in all stages of cancer progression and has an important role during tumour cell proliferation, survival and progression, controlling the generation of epithelial polarity, junction assembly and disruption of epithelial cells. Furthermore, RhoA is important for both amoeboid and mesenchymal migration through the activation of the RhoA-ROCK signalling pathway (Tseliou et al. 2016).

Invasive cancer cells must be capable of assembling invadosome structures termed invadopodia that represent sites of focal matrix metalloproteinase (MMP) secretion. MMPs, invasive cancer cells generate 
traction force at the rear, with the protrusive process of invadopodia formation occurring at the front, enabling cells to propel through the degraded ECM/stromal barrier. MMP2 and MMP9 have roles in angiogenesis and epithelial to mesenchymal transition (EMT). Owing to their roles in cell invasion, invadopodia are believed to be the sites of focal secretion of MMP2 and MMP9 (Grauzam et al. 2018).

For almost the past two decades, there have been many advances and rapid increases in imaging techniques used for cell biology. These advances have been the result of contributions from crossdisciplinary scientists in different fields. Physicists have provided much of the technology, such as the advanced electron detectors that increased the speed and sensitivity of modern electron microscopy instruments. Chemists have developed brighter fluorescent probes that illuminate targets for longer. Statisticians and computer scientists together have improved image processing and analysis techniques. This sort of acceleration in imaging has come about through these interdisciplinary efforts (Fleming 2014). Among these imaging techniques, Atomic Force Microscopy (AFM) and Scanning Electron Microscopy (SEM) combined with Energy Dispersive Spectroscopy (EDS) are the most widespread types of imaging techniques. When they are especially considered together with X-ray Photoelectron Spectroscopy (XPS), results are better interpreted. Briefly, in a SEM microscope, a beam of electrons moves back and forth across a cell's surface, creating details of cell surface characteristics and SEM has found applications in different cell types from embryonic stem cells (Baharvand and Matthaei 2003; Bergert et al. 2021) to cancerous cells (Boyde et al. 1972; Beil et al. 2005; Franchi et al. 2020; Palumbo et al. 2020). AFM is a well-known high-resolution three-dimensional (3D) surface imaging technique that has been used especially in cancer research allows to get detailed topographical knowledge by scanning cell surfaces (Lin et al. 2007; Sirghi et al. 2008; Polyakov et al. 2011; Steffen and Koehler 2018; Li et al. 2021). XPS is a surface-sensitive technique and sampling depth is about $10 \mathrm{~nm}$ when the sample surface is positioned normal to the detector. This size means that the sampling depth is larger than the dimensions of many adsorbed proteins and biomolecules. This allows for signals from a substrate and an adsorbed (i.e., protein) overlayer to be detected simultaneously (McArthur et al. 2014a).

AFM further reveals the underlying nature of the cell components at cellular level. Recently, researchers were able to better extend their knowledge on the changes in cell structure including formation of filopodia, lamellipodia, stress fiber and stellation by AFM (Tiryaki et al. 2012). It was also revealed that surfaces of formaldehyde-fixed astrocytes differed by protrusions in $L$ and by a HS-dependent fibrillar network in $\mathrm{M}$ glia indicating the correlations between cell surface morphology and functional properties (Weissmüller et al. 2000). The membrane structure and mechanical behaviour of cells has been investigated by AFM and it was shown that cancerous cells have different biophysical features in comparison to normal cells. It enables the extraction of topographical, mechanical and physicochemical properties such as elasticity (Guo et al. 2012), friction (Sirghi et al. 2009) or adhesion forces (Smith et al. 2013) and roughness (Kaul-Ghanekar et al. 2009) in biological systems in their natural environment. In addition, AFM has been widely used in the study of cell biology in order to reveal the relationship between cell functions and biophysical alterations (McEwen et al. 2013). AFM studies of living cells and cellular structures give significant knowledge about the viscoelastic features of the cell membrane and cell cytoskeleton organization. For cellular systems, information about micromechanical features is essential 
because it assists to figure out cell architecture and its functions. This powerful technique has the capability to visualize cellular ultrastructure, down to the level of structures such as the nuclear pore (Oberleithner et al. 1994) and cytoskeletal fibers (Cheng and Wang 2008) as well. Several works (Lam et al. 2007; Suresh 2007b, a) indicate that AFM could be efficiently used in the early diagnosis of cancer by using nano-biomechanical properties. Lekka et al. investigated the elasticity of normal human bladder epithelial cells (Hu609 and HCV29) and cancerous ones (Hu456, T24 and BC3726) by using AFM. They found that normal cells are much stiffer than cancer cells and concluded that this is attributed to the reorganization of the cytoskeleton (Lekka et al. 1999). Previous studies using AFM showed that the cancer cell lines have rougher surface and lower elasticity than benign cell lines ( $\mathrm{Li}$ et al. 2008; Wang et al. 2016). As a supportive and complementary to AFM, another imaging technique, SEM, provides information about the structures of cells with its high-resolution imaging feature and is also used in cancer research. (Boyde et al. 1972; Li et al. 2008) When SEM is also combined with EDS, it is possible to use it for extracting semi-quantitative elemental map of the region of interest under investigation.

In addition to mentioned imaging techniques above, surface elemental characterization can be also investigated by XPS. This technique is used for bio-relevant or biological samples. Moreover, it can be used to determine certain functional groups related to a specific element. Regarding carbon, $\mathrm{CH}_{\mathrm{x}}, \mathrm{C}-\mathrm{O}$, $\mathrm{C}=\mathrm{O}$, and $\mathrm{O}-\mathrm{C}=\mathrm{O}$ can be distinguished because of variations in the functional group's electronegativity, yielding a shift in the relative energy of their ejected photoelectron (McArthur et al. 2014a; Skallberg et al. 2017). The analysis of both elemental and chemical properties of the cell surface was also previously reported (McArthur et al. 2014b; Scimeca et al. 2018). Skallberg et al. used the XPS on the surface of blood cells, but no comparison was made between GBM and astrocyte using XPS in the literature (Skallberg et al. 2017).

Together with the development of new techniques that opened novel avenues of the cell research, both the current status, and future directions of this rapidly growing area of science strongly depend on further investigation of cell characteristics in great details by multi analytical techniques. For this reason, we used AFM to investigate the differences of the cell surfaces of the astrocytes and GBMs by using roughness and the height data for revealing the general morphologic characteristics of these cells. Furthermore, two spectroscopic techniques, XPS and EDS, were both performed in order to characterize the cells' elemental composition and morphology. Besides, it is of particular importance to distinguish the signals observed in XPS spectra caused by fundamental structures like phospholipids, molecules in cytoplasm, and DNA. Thus, observing such structures and their corresponding abundances may eventually play a key role for early diagnosis and the evolution stage tracking of the cancerous cells.

\section{Materials And Methods}

\subsection{Cell Culture}


Human astrocyte cell line SVGp12 (ATCC® CRL-8621TM) and astrocytoma cancer (glioblastoma) cell line U-87MG (ATCC® HTB-14 TM) (American Type Culture Collection (ATCC)) were cultured in EMEM (Eagle's Minimum Essential Medium) (ATCC 30ß-2003TM) medium containing 10\% fetal bovine serum (Biowest, S1810). Cells were maintained in the incubator containing $5 \% \mathrm{CO}_{2}$ at $37^{\circ} \mathrm{C}$. Cell lines were monitored daily by inverted microscope for viability, proliferation, and infection. The arrival of the cell lines to the laboratory was accepted as p1 and p4 passage numbers were used in the experiments. When the cell density was more than $80 \%$, the cells were passaged. Cell counting was performed with Muse ${ }^{\circledR}$ Cell Analyzer.

\subsection{Real-Time Polymerase Chain Reaction (RT-PCR)}

The cells were rinsed with 1X Phosphate-buffered saline (PBS) after detached from the surface with 0.25\% Trypsin-EDTA solution and dissolved in RNA buffer. Before RNA isolation, the purity of the samples was controlled. RNA isolation was performed according to the Roche isolation protocol and RT-PCR achieved with a customized Roche panel.

\subsection{F-actin Immunofluorescence Staining}

The cells were seeded $10^{5}$ cells $/ \mathrm{ml}$ at the start and incubated in complete medium for 48 hours on 15 $\mathrm{mm}$ round coverslips. They were fixed with $4 \%$ paraformaldehyde and rinsed three times with $1 \mathrm{X}$ PBS and permeabilized with $0.25 \%$ TritonX-100 in $1 \mathrm{X}$ PBS. The cells were incubated with $1 \%$ BSA in $1 \mathrm{X}$ PBS for 1 hour for blocking. Phalloidin 488 (abcam, ab176753) were diluted in \%1 BSA in 1X PBS. The cells were incubated with the phalloidin for 1 hour and mounted with Fluoroshield Mounting Medium with DAPI (abcam, ab104139). Sample imaging was performed by Olympus BX-51 microscope (Olympus Optical Co., Tokyo, Japan).

\subsection{Atomic Force Microscopy (AFM)}

GBM and astrocyte cells were seeded $10^{5}$ cells/ml for AFM investigations. The cells were incubated in complete medium for 48 hours on $15 \mathrm{~mm}$ round coverslips before AFM imaging. The cells were fixed with 4\% paraformaldehyde and rinsed three times with distilled water. Excess water was drained 5 minutes prior to imaging and left for drying. When the excess water on the sample evaporated, the sample was inserted to the stage in the instrument.

Bruker Dimension Edge with ScanAsyst AFM (Bruker, Germany) instrument was used to obtain 2D and 3D images in PeakForce Tapping mode in the air at ambient temperature. For this mode, ScanAsyst-Air cantilevers with a spring constant of $0.4 \mathrm{~N} / \mathrm{m}$ and frequency of $70 \mathrm{kHz}$ (Bruker, Germany) were used. A scanning area of $100 \times 100 \mu \mathrm{m}^{2}$ with a scan rate of $1.0 \mathrm{~Hz}$. was selected. Image analysis was performed by NanoScope Analysis 1.5 Software (Bruker, Germany). Maximum height $\left(R_{\max }\right)$, root-mean-square roughness $\left(R_{r m s}\right.$ or $\left.R_{q}\right)$ and average roughness $\left(R_{a}\right)$ data were calculated. $R_{q}$ and $R_{a}$ were defined by formulæ below: 


$$
\begin{gathered}
R_{q}=\sqrt{\frac{\sum_{i=1}^{N}\left(Z_{i}-\bar{Z}\right)^{2}}{N}} \\
R_{a}=\frac{1}{N} \sum_{i=1}^{N}\left|Z_{i}\right|
\end{gathered}
$$

where $Z_{i}$ is the current height value; $\bar{Z}$, the mean height value; $\mathrm{N}$, the number of points within the selected region of a given area.

\subsection{Scanning Electron Microscopy/Energy Dispersive X-ray Spectroscopy (SEM/EDS)}

GBM and astrocyte cells were seeded at $10^{5}$ cells $/ \mathrm{ml}$ and fixed after 48 hours incubation within $4 \%$ paraformaldehyde and stored in PBS. Prior to the SEM imaging and analysis samples were completely dried in dry air. Before imaging work of the cells, a $6 \mathrm{~nm}$ gold-palladium coating was applied on all samples by using Leica EM ACE600 sputter coater under vacuum approximately 30 minutes with argon gas (Leica Microsystems, Germany) to make the surfaces of these cells conductive prior to SEM imaging. Imaging resolution of $0.9 \mathrm{~nm}$ and acceleration voltage of $1 \mathrm{kV}$ were used. SEM/EDS imaging was acquired using Thermo Scientific Apreo S LoVac SEM (ThermoFisher Scientific, U.S.A.) equipped with Schottky Field Emission Gun. Images were collected in high vacuum mode. For the measurements, maximum beam of current of $50 \mathrm{nA}$ and $30 \mathrm{kV}$ accelerating potential were used, respectively. EDS detector (EDAX, AMETEK, U.S.A.) that was implemented into the SEM device was used to analyse elemental spectra from each cell. ImageJ $(1.53 \mathrm{~g})$ public domain Java image processing program for Windows was used for the calculation of the lengths for the filopodial and lamellipodial protrusions observed in the SEM images (Rasband; Abràmoff et al. 2004; Schneider et al. 2012).

\subsection{X-ray Photoelectron Spectroscopy (XPS)}

GBM and astrocyte cells were seeded at $10^{5}$ cells $/ \mathrm{ml}$ and fixed after 72 hours incubation within $4 \%$ PFA and stored in PBS. Cells were fixed with $4 \%$ PFA then incubated in 1 X PBS at $+4{ }^{\circ} \mathrm{C}$ for XPS elemental analysis. Prior to analysis, the cells were rinsed three times with distilled water and dried under vacuum. Cells were seeded on the copper tape surface to eliminate contributions from $\mathrm{Si}, \mathrm{Ti}, \mathrm{C}$ and $\mathrm{O}$ atoms due to the background. K-Alpha X-Ray photoelectron spectrometer (Thermo Fisher Scientific, U.K.) was used for the experiments. Al $\mathrm{K}_{\mathrm{a}}$ monochromatic (1486.68 eV) was used as an X-ray source, and a $180^{\circ}$ semicircular analysor with a detector of 128 channels was used for the measurements. The size of the X-ray spot and sampling area were $300 \mu \mathrm{m}$ and 60 × $60 \mathrm{~mm}$, respectively. Relative elemental atomic ratio was obtained by Thermo Scientific K-Alpha point analysis.

\subsection{Statistical Analysis}


Gene expression profiles were analysed with the 'Multiple Plate Analysis' program. The reference housekeeping genes expression ( $\beta$-actin, glyceraldehyde 3-phosphate dehydrogenase) for normalization were assayed for relative quantification. Fold change was calculated according to $2^{-\Delta \Delta \mathrm{Ct}}$. Experimental groups were compared according to the t-test statistical analysis and fold change values were evaluated whether the value was under or over the 2-fold. F-actin intensity measurements were achieved by ImageJ/Fiji program (Image analysis software, National Institutes of Health, Bethesda, MD) (Oltulu et al. 2019). The analysis of F-actin intensities and aspect ratio were performed using JMP Pro software Version 13.0 (SAS Institute Inc., 2017). IBM SPSS Statistics 25.0 was used for evaluation of the data. The data were evaluated with Shapiro Wilk test for normality and Levene's test for equality of variances. Samples with normal distribution were evaluated with the Independent Samples t-test, while samples without normal distribution were evaluated with Man Whitney-U test. Results were given as mean \pm standard deviation (SD), unless otherwise indicated. $p<0.05$ was considered to be statistically significant.

\section{Results}

\subsection{Surface morphology and comparison of GBM and astrocyte cells}

GBM cells are astrocytic carcinoma and could share similar characteristics due to their source of origin both astrocytic. Close-up inspection of phase contrast images given in Figure 1 for GBM and astrocyte cells. Both cell lines have numerous sprouts from the cell body; however, astrocytes were more spread. The astrocytes covered the surface area with thinner cell body, while GBM cells prefer to be more spindle shaped. Cells were imaged under $40 x$ magnification (scale bar is $20 \mu \mathrm{m}$ ).

\subsection{GBM and astrocytes diverge at the level of gene expression related to motility}

Here, we investigated the GBM, and astrocytes morphology, topology and elemental composition and the similarities and differences will lead to alterations of cytoskeleton and motility related gene expressions. The genes related with the invasion CDC42, MMP9, MMP2, RHOA and GFAP were evaluated with RT-PCR (Table 1). The expressions of these genes were significantly high in GBM; however, ARPC2 and ROCK1 gene expressions were similar to astrocytes.

\subsection{GBM cells have elevated level of F-actin intensity than astrocytes and not organize in the same pattern}

F-actin is a cytoskeletal component and displays cellular morphology. Here, the distribution of the actin filaments was different in the means of the localization. Astrocytes displayed parallel actin filaments, however, GBM cells showed more actin filaments on the edge of the cells as stress fibres (Figure 2A, 2B). Besides, GBM cells displayed actin dots (actin puncta) on lamellipodial area. The comparison of the Factin intensity reveals that there was a significant difference between the GBM and astrocyte cells; GBM cells showed wide range values which means GBM cells modulate the cytoskeleton more than astrocytes (Figure 2C). 
The shape of the cells could be figured out with the actin staining. We also calculated the aspect ratio of these two cell lines to conclude the differences of the cell shape. The aspect ratio is the ratio of major to minor axis of the cell length. The aspect ratio of GBM is higher $(4.19 \pm 1.49)$ than astrocytes $(1.85 \pm 0.63)$ (Figure 2D). We could conclude that GBM cells were spindle shaped morphology while astrocytes were more spread to the surface.

\subsection{Topographic and morphologic features of GBM and astrocytes cells by AFM}

AFM was used to obtain detailed information about the topographical and morphological features of glioblastoma multiforme (GBM) and astrocyte cells. Three-dimensional (3D) high-resolution nanotopographic images of cancer cells (GBM) and healthy cells (astrocyte) were shown in Figure $3 A$ and $B$, respectively, while the root mean square roughness $\left(R_{\mathrm{q}}\right)$, average roughness $\left(R_{\mathrm{a}}\right)$ and maximum height $\left(R_{\max }\right)$ data of GBM and astrocyte cells were given in Fig. 3C, D and E, respectively. GBM cells were morphologically longer and narrower when compared to astrocyte cells which were shorter and more disseminated. As shown in Figure 3A and B, both GBM and astrocyte cells formed a membranous structure with cellular extensions, and they were firmly attached to the surface. Astrocyte cells exhibited a distinct elevation in the nucleus region and spreading morphology in other cell regions.

We also investigated cell spreading and filopodia formation by AFM. As seen in representative 3D images in Figure 3B, numerous well-organized lamellipodia around the edges of astrocyte cells, with the short filopodial protrusions growing from these areas. Lengths of these filopodial formations were found to be approximately $5 \mu \mathrm{m}$. Careful investigation of these structures revealed that the average heights of these filopodial formations are $50 \mu \mathrm{m}$. However, we observed some filopodia with different lengths, indicating different possible growth stages. In addition, these protrusions were also observed for GBM cells in Figure $3 \mathrm{~A}$, but not as clear as astrocyte cells.

The root-mean square roughness $\left(R_{q}\right)$, average roughness $\left(R_{a}\right)$ and maximum height $\left(R_{\text {max }}\right)$ data for GBM and astrocyte cells were given in Table 2. As seen from Table 2, roughness values of both GBM $(49.17 \pm 18.12 \mathrm{~nm})$ and astrocyte cells $(46.77 \pm 21.31 \mathrm{~nm})$ are relatively close to each other, whereas the maximum height profile of astrocyte cell $(1322.67 \pm 381.78 \mathrm{~nm})$ is slightly greater than GBM $(1024.70 \pm 224.39 \mathrm{~nm})$. These alterations might be the result of dysregulation in the cytoskeleton, thus contributing to cancerous cell evolution.

\subsection{Structural details of the filopodial and lamellipodial protrusions by SEM-EDS}

By SEM-EDS we were able to examine the details of the microenvironment of the investigated cells, revealed elemental composition and gave better understanding of the structures and invasion profiles of the protrusions. In order to distinguish the GBM and the astrocyte cells, a careful analysis for the morphologies of these cells determined from SEM images were performed. Working distance for the samples were 12.1 and $8.9 \mathrm{~mm}$ for GBM and astrocyte, respectively. Accelerating voltage for the electron beams were high voltage of $5 \mathrm{kV}$ for all the cells. However, GBM was imaged at 3250x whereas astrocytes were imaged at 5000x. Based on this analysis, GBM cells appeared as more elongated shapes 
with several filopodial protrusions at the edges of the cells and small protrusions throughout the cell body. As correlates with the phase-contrast microscopy, astrocytes displayed more radially spreading out fashion in cell morphology when compared to GBM cells with spindle like morphology. In addition, astrocytes showed multivesicular-like cytoplasmic structures distributed on the lamellipodial area with the varying shapes and sizes. The surface of the cell was rougher in the lamellipodial area in astrocytes, whereas the rough area was better described in GBM cells in the nuclear region (Figure 4A-B). The average lengths of the almost needle-like filopodial structures were calculated as $3.28 \mu \mathrm{m}$ for GBM cells whereas $2.84 \mu \mathrm{m}$ for astrocytes.

Prior to EDS point analysis of compared GBM and astrocyte cells, samples were coated with Au/Pd particles for imaging. Elemental composition spectra data on the cell surface were detected after removing Au spectrum (Supp Table 1 and Figure 4C). As the cell itself possesses a non-conducting nature (Morgan 1985), SEM imaging technique causes a charging issue on the cell due to its accelerating electrons. Thus, the image quality is greatly decreased. To overcome this situation, gold and platinum are coated for the non-conducting samples. Elemental weight percentages obtained from EDS findings were also analysed by Students' t-test $(p<0.05)$. According to results, nine elemental weight ratios were statistically close to each other in GBM and astrocytes. Based on the results presented in Supp Table 1, the most abundant elements detected by EDS were $\mathrm{C}$ and $\mathrm{O}$. The remaining elements appeared in small portion of intensity as presented in Supp Table 1. However, it should be emphasized that the amount of Si was originated from the substrate. Regarding the two most abundant contributing elements, $\mathrm{O}$ and $\mathrm{C}$ ( 37.65 and $31.23 \%$, respectively), we can conclude that these two are the most representative vital elements of the cells we investigated. It is also known that the most representative elements that exist in proteins are $\mathrm{C}, \mathrm{N}$, and $\mathrm{O}$ but cells can also contain low levels of other elements including sulphur, phosphorus, and various metals. Elemental contributions lower than $5 \%$ were not taken into consideration except the potassium ratio (3.03\% for GBM and $4.36 \%$ for astrocyte) since the potassium channels are attributed to cancer cases where these channels are known to be highly active (Comes et al. 2015).

\subsection{Elemental analysis and bonding types for the functional group assignments by XPS}

XPS can probe the cell surface and it reveals detailed information on the elemental composition of the cell. The binding energy of the photoelectrons used in XPS strongly depends on the chemical state of the element which makes different sorts of bonding with the neighbouring atoms. Thus, chemical shifts observed in the XPS spectra represent different chemical functional groups. Here, we determined the elemental abundances over the surfaces of the GBM and astrocyte cells. Findings were presented in Supp Figure 1 and the specific elements were listed as atomic percentages (\%) (Supp Table 2).

XPS analysis revealed that the most weight \% signals come from the $\mathrm{C}, \mathrm{N}$, and $\mathrm{O}$. The carbon shifts lead to different bonding of carbon in structures of molecules. In general, an observed C1s peak in XPS spectra is attributed to four components: i) component due to carbon bound only to carbon and hydrogen $(\mathrm{C}-(\mathrm{C}, \mathrm{H})$, mainly at $284.8 \mathrm{eV}), \mathrm{ii})$ a component at $286.3 \pm 0.1 \mathrm{eV}$ due to carbon making a single bond with oxygen or nitrogen $(\mathrm{C}-(\mathrm{O}, \mathrm{N}))$, iii) a component at $288.0 \pm 0.1 \mathrm{eV}$ due to carbon making two bonds with 
oxygen, two single bonds or one double bond $(\mathrm{C}=0)$, and finally iv) a weak component or a shoulder caused by $\mathrm{O}=\mathrm{C}-\mathrm{OH}$. Regarding 01s peak in XPS spectra, two components can be distinguished: i) a component at $531.3 \pm 0.2 \mathrm{eV}$, associated with oxygen making a double bond with carbon $(\mathrm{C}=0)$, ii) a component at $532.6 \mathrm{eV}$ due to alcohol $(\mathrm{C}-\mathrm{OH})$ in general. In addition, main N1s peak is observed at 399.6 $\pm 0.3 \mathrm{eV}$ (amine or amide) with an accompanying satellite peak at $401.3 \mathrm{eV}$ due to protonated nitrogen (Rouxhet et al. 1994). The approximate peak binding energies of bonding of $\mathrm{C}, \mathrm{O}$ and $\mathrm{N}$ elements, that was previously reported (Skallberg et al. 2017) could be listed as C1s (284.0-290.0 eV), 01s (527.0-537.0 $\mathrm{eV}$ ) and $\mathrm{N} 1 \mathrm{~s}(399.0-400.0 \mathrm{eV})$ as shown in Figure 5 and their spectral regions according to their chemical state could be listed as C-C (284.0-285.0), C-N/O (285.8- 286.2 eV), O-C=O ( 288 eV), C=O (288-290 eV), $\mathrm{C}-\mathrm{NH}_{2}(388-400 \mathrm{eV}), \mathrm{C}=\mathrm{O}(531.4-531.8 \mathrm{eV}), \mathrm{C}-\mathrm{O}(532.5-532.9 \mathrm{eV})$ and metal carbonates $(530.7 \mathrm{eV})$.

Although it is not an easy task to define exact chemical shifts and their corresponding functional groups, we can suggest that chemical shift of $\mathrm{C} 1 \mathrm{~s}$ in photoemission are used to identify vital components of the cell structure. Strong $\mathrm{C} 1 \mathrm{~s}(\mathrm{C}-\mathrm{C})$ signal is particularly associated with the region where the high density of phospholipids is found in the cell membrane. However, C1s (C-N) and C1s (C-O) signals are acquired from the cell core where the cytoplasm and DNA are found in cell nucleus (Skallberg et al. 2017).

Atomic elemental ratio of GBM and astrocyte cells were compared with Students' t-test $(p<0.05)$ according to XPS point measurement results. The six elements were mainly detected on the surface (Figure 6, Supp Table 2). These elements can be listed as P, S, C, N, O, Na. The abundance of $\mathrm{C}$ and $\mathrm{O}$ elements are approximately similar in these cells $(\sim 1$ atomic\%) and the atomic\% of the $\mathrm{P}$ is almost double the GBM $(0.84 \%)$ compared to astrocyte $(0.42 \%)$. Moreover, atomic\% of S for GBM $(0.31 \%)$ is almost 1.5 times higher than the astrocyte $(0.19 \%)$. Nitrogen is less in GBM than astrocyte cells but is not statistically different. We found zero contribution from $\mathrm{Na}$ element for astrocytes whereas the atomic \% of GBM was found to be $0.82 \%$. This finding is related to the penetration depth capability of XPS instrument which is around $0-10 \mathrm{~nm}$ from the top of the surface of the sample.

Four different spots (A, B, C, and D) over GBM and astrocyte cells were scanned in XPS survey for the carbon whereas one spot for nitrogen and two spots for oxygen for both cells. As presented in Supp Table 3 , peak positions were seen in line with the previous reported data. (Rouxhet et al. 1994; Ahimou et al. 2007; Skallberg et al. 2017)

Nitrogen peak (399.78 eV) for GBM and (399.71 eV) for astrocyte was not decomposed into two contributions as stated in a previous XPS study (Ahimou et al. 2007). These two contributions were reported due to 1) characteristic of nonprotonated nitrogen (399.8 eV, typical of amide and amine) and 2) protonated nitrogen ( $401.3 \mathrm{eV}$, typical of ammonium or protonated amine). We observed one single wellresolved peak for nitrogen at 399.78 (FWHM is $3.74 \mathrm{eV}$ ) and $399.71 \mathrm{eV}$ (FWHM is $4.32 \mathrm{eV}$ ) for GBM and astrocytes, respectively which agree with the literature.

Oxygen peaks for GBM (531.68 eV) was decomposed into two components: 1) $531.68 \mathrm{eV}$ attributed to oxygen making a double bond with carbon (including amide and carboxyl) and oxygen of carboxylate, and 2) $533.56 \mathrm{eV}$ attributed to single bond constructing oxygen with hydrogen or carbon (C-O-H of 
alcohol and carboxyl, C-O-C of acetal and hemiacetal) (Ahimou, 2007). This decomposition was not observed for astrocytes. However, FWHMs of GBM and astrocytes for both regions (A and B) were the same (2.9979 and $3.5074 \mathrm{eV})$. Furthermore, intensity data for both cells and both regions were close to each other. As for carbon contribution.

Carbon FWHM peaks were observed between 1.0801 and $2.2431 \mathrm{eV}$ for GBM and 0.6827 and 1.8331 for astrocytes, respectively. This observation is in contrast with previously reported findings (Rouxhet et al. 1994) of FWHM range $1.35-1.60 \mathrm{eV}$ for C1s components. When molar ratios (Supp. Table 4) were compared to total carbon obtained by our XPS survey (Supp Table 2), astrocytes were seen to be distinguished based on their $\mathrm{P} / \mathrm{C}$ and $\mathrm{S} / \mathrm{C}$ molar ratios. Based on our findings, we can say that N/C molar ratio of $0.07 \%$ for GBM cells compared to astrocytes $(0.10 \%)$. This suggest the existence of chitin (Rouxhet et al. 1994), a polysaccharide as an amide derivative of glucose which is a primary component of cell walls (Tang et al. 2015). Chitin nitrogen molar ratio based on nitrogen/carbon was reported as 0.125 for microbial surfaces (Rouxhet et al. 1994). In mammals, there was no recorded existence of endogenous chitin, however, chitinase-like proteins have been characterised (Lee et al. 2011). Abundance of chitin-like proteins in GBM cells questionable from this data.

\section{Discussion}

It is crucial to further understand the molecular changes taking place on the surface of the cell and its microenvironment to contribute cancer biology and thus create possible therapeutic targets. It is already proven that the molecular biological investigations supported with high-resolution imaging and selected effective spectroscopic methods increased the depth of the investigations and contributed to the identification of differences of the cells, i.e., somatic cells, stem cells and cancer cells.

F-actin (microfilament) is one of the key elements of the cytoskeleton and contributes to spines morphogenesis (Kim 2009). The dendritic sprouts through the cell body contain F-actin components in which these structures were led by small GTPases like Cdc42 (Kim 2009). Cdcd42 was one of the members of Rho family GTPase reviewed as one of the key proteins in invasion migration and take part in invadopodium process (Al-Koussa et al. 2020). Rho-associated GTPases are effective in many cell functions. While they are involved in important mechanisms such as cycle maintenance and survival, they also play effective role in changes in cell shape, movement and adhesion (Yang et al. 2001). CDC42 is particularly effective in cell polarity and filopodia formation. In addition to axon formation and myelinization in the nervous system, it is also effective for cytoskeletal regulation and neuronal polarity (Murali and Rajalingam 2014). Higher gene expression of CDC42 relative to astrocytes in GBM may refer to cancer cells motility or features such as invasion.

While RhoA functions in the polarity of normal epithelial cells, it is also effective in many stages of cancer progression and is generally found to increase in tumours (Murali and Rajalingam 2014). An expected increase of RhoA was seen in GBM relative to astrocytes. Actin is the main factor in the organization of the cell shape, structure and polarity and dynamically undergoes remodelling. Rho GTPases are involved 
in the actin based cellular protrusions or structures such as lamellipodia, filopodia, stress fibers and focal adhesion (Aspenström et al. 2007). The increase in GBM of Rho GTPases such as RhoA and CDC42 coincides with the higher F-actin intensity in GBM. The breakdown and remodelling of the extracellular matrix are required for the cell movement. Matrix metalloproteinases (MMP) are proteases used for these functions. Membrane MMPs that are effective in mesenchymal cell movement, such as MMP-2 and MMP-9, are regulated by Rho GTPases (Murali and Rajalingam 2014). EMT occurs in invasion and metastasis, are main characteristics of cancer and closely related to prognosis. Mesenchymal-epithelial transition (MET) with EMT allows access to the new microenvironment, and they are the main mechanisms of distant organ metastases. MMP-2 and MMP-9 play role in facilitating EMT by causing the breakdown of the E-cadherin (Radisky et al. 2005). Taking all these under consideration as expected increase of MMP-2 and MMP-9 gene level were seen in GBM relative to astrocyte.

In our study, astrocytes and GBM cells were also compared by means of AFM, SEM/EDS and XPS techniques and the differences between these cells were observed by these complementary techniques. Two previous works focused on the breast epithelial cells and examined roughness data on these cells' surfaces (Li et al. 2008; Wang et al. 2016). Another work demonstrated that urothelial cancer cells were rougher than healthy urothelial ones (Canetta et al. 2014). Furthermore, our recently published investigation on mouse embryonic stem cell (mESC), mouse skin fibroblast (MSF) and mouse lung squamous carcinoma cell (KLN-205) also took advantages of such complementary techniques to reveal the cells' surface roughness and elemental compositions (Ozdil et al. 2021). The morphology and topology of the cell could be modulated by differential surface characters for instance stiffness (Mullen et al. 2014; Chang et al. 2017) and nano-topology (Liliom et al. 2019; Hou et al. 2020). Hence, the signal coming from the out of the cell alters the inner processes of the cell.

Here, we investigated cancer (GBM) and healthy (astrocyte) cells at the same conditions on the glass substrate surface. Although the AFM results provided that the maximum height of the astrocytes was higher than GBM cells, both phase contrast and AFM and SEM images clearly showed that only the nuclear part of the astrocytes appeared high, and the perinuclear area was rather low and widespread. On the other hand, GBM cells appeared to be high in both nuclear and perinuclear regions. While both cells exhibited elongated structures, astrocytes have a wider membrane (spread morphology) than GBM cells which were more spindle shaped. Hence the aspect ratio of the GBM cells was higher than astrocytes. Both cell groups have lamellipodial areas, however, this area was at all cell borders in astrocytes and at the extreme points of spindled shaped elongated cells in GBM cells. GBM cells have fine spindle protrusions along the cell body where the lamellipodial area was not apparent.

In an AFM research to investigate the apoptotic changes in the morphology of the rat cortical astrocyte cell (CTX TNA2), it was found that the mean height of apoptotic cells was approximately twice that of untreated normal cells which were an indication of a correlation between antigen treatment and cell height. According to results of that work, it was found that the height of the astrocyte cell was $1.999 \pm 0.217 \mu \mathrm{m}$ whereas the height of the apoptotic astrocyte cell was $4.296 \pm 0.410 \mu \mathrm{m}$. It has been also shown that the normal shape of the astrocyte cell changed upon treatment was transformed to almost 
rounded structures which was a clear effect of treatment. Findings of that study revealed that apoptosis of astrocyte cell might cause many types of neurodegenerative disorders such as cerebral ischemia, Alzheimer's and Parkinson's diseases (Hsiao et al. 2013). Our results demonstrated that the height of astrocyte cells are $1.322 \pm 0.381 \mu \mathrm{m}$ which is in consistency with the results presented by Hsiao et al. (Hsiao et al. 2013). However, regarding GBM cells, we found their height to be $1.024 \pm 0.224 \mathrm{~nm}$, which is smaller than the reported by Hsiao et al. (Hsiao et al. 2013). This difference in GMB cell height might be associated with grade levels, high or low, of the cells under study or the type of the cell depending on whether it is rat or human. In order to reveal the ultrastructural correlates of enhanced oxidative stress during hyperoxia, D'Agostino et al. (D'Agostino et al. 2009) examined the physical changes in plasma membrane roughness on U87 human glioma cells by using AFM. These cells were subjected to 0.20 atmosphere absolute (ATA) $\mathrm{O}_{2}$, normobaric hyperoxia $\left(0.95 \mathrm{ATA} \mathrm{O}_{2}\right)$ or hyperbaric hyperoxia $(\mathrm{HBO} 2,3.25$ ATA $\mathrm{O}_{2}$ ). Furthermore, 0.2 and $2 \mathrm{mM} \mathrm{H}_{2} \mathrm{O}_{2}$ was utilized as a positive control for membrane lipid peroxidation. Based on the results, the roughness $\left(R_{a}\right)$ of the plasma membrane was determined to be $34 \pm 3,57 \pm 3$ and $63 \pm 5 \mathrm{~nm}$ in $0.20 \mathrm{ATA} \mathrm{O}_{2}, 0.95 \mathrm{ATA} \mathrm{O}_{2}$ and $\mathrm{HBO}_{2}$, respectively where $0.20 \mathrm{ATA} \mathrm{O}_{2}$ presumably reflected the normal ultrastructural properties of healthy U87 cells. Additionally, roughness values for 0.2 and $2 \mathrm{mM} \mathrm{H}_{2} \mathrm{O}_{2}$ were found to be $56 \pm 7$ and $138 \pm 14 \mathrm{~nm}$, respectively. Based on our results, roughness of U-87MG (GBM) and SVGp12 (astrocyte) cells are $49.17 \pm 18.12 \mathrm{~nm} 46.77 \pm 21.31 \mathrm{~nm}$, respectively. When compared to the results of D'Agostino et al. (D'Agostino et al. 2009), we can suggest that our roughness result for $\mathrm{U}-87 \mathrm{MG}$ cell is consistent with their roughness value for the same cell line.

A previous study highlighted the height profiles of lamellipodia structures of non-neoplastic astrocyte control cells (CC-2565 and SC-1800) and glioma cells (SNB-19, UP-007 and SEBTA-048) by using Quantitative Imaging (QI) $®$ mode AFM. Lamellipodia heights of glioma cells (SNB-19 and UP-007) were $2.45 \pm 0.59$ and $1.57 \pm 0.42 \mu \mathrm{m}$ while these heights were $1.03 \pm 0.58$ and $0.85 \pm 0.40 \mu \mathrm{m}$ for astrocyte cells (CC-2565 and SC-1800), respectively. However, lamellipodia height $(1.16 \pm 0.48 \mu \mathrm{m})$ of SEBTA-048 glioma cell was found to be as same as astrocytes. Besides, the nucleus height of SC-1800 astrocyte cell was determined to be $5.73 \mu \mathrm{m}$ which is higher than the neighbouring observed lamellipodia height. These height differences of different cells were associated with the invasive potential degree between these cell lines. Besides, lamellipodia heights of high-grade cells have been found to be higher than non-neoplastic astrocyte control cells. By contrast, lamellipodia heights of low-grade glioma cells were equal to lamellipodia heights of astrocyte cells but less than those of GBMs. These findings indicate that the lamellipodia heights of different cells can provide new insight on monitoring and controlling cellular invasion in brain tumours (Smith et al. 2016). Zhou et al. (Zhou et al. 2008) reported the characteristic structure of cytoskeleton in $\mathrm{C} 6$ glioma cells and compared to the cytoskeleton system of rat astrocyte. Three-dimensional (3D) imaging obtained by AFM deduced that the cytoskeleton system of $\mathrm{C} 6$ glioma cells is a network structure which radiated from the nucleus centre towards the periphery with an irregular edge root whereas this network in astrocytes is a regular and smooth edge (Zhou et al. 2008). In another study, to illustrate the effect of cold plasma on cell shape and morphology by AFM imaging technique, normal human astrocytes (E6/E7) and human brain glioblastoma cells (U87) before and after plasma treatment were used. Results demonstrated that U87 cells are observed as smooth and rounded, with 
small protrusions while E6/E7 cells are rough and highlight the smaller, sharper features on the cell surface. After 48 and 72 hours of treatment, significant differences were observed in cellular morphology of U87 cells and almost no differences on E6/E7 cell shape and morphology were seen. In addition, 3D topographic images of these cells indicate the height profiles to be $1 \mu \mathrm{m}$ for E6/E7 cells and $2 \mu \mathrm{m}$ for U87 cells, respectively (Recek et al. 2015). Besides, filopodia formations are associated with the expanding of directed cell migration and thus they are important components for cell motility. For this reason, we also focused on cell spreading and filopodia formation for GBM and astrocyte cells by AFM. In short, we found that the lengths of filopodial formations and heights of them are approximately 5 and $50 \mu \mathrm{m}$ for astrocyte cells and this is in line with the previously reported data. However, these structural parameters, height and length, were observed for GBM cells but not clearly were identified.

In SEM/EDS experiment, it is known that the electron beam penetration depth lays typically in the range from 10-100 nm for a wide variety of nanomaterials above $2 \mathrm{kV}$. As the accelerating voltage is higher, the penetration depth is larger. The electron beam thus can fill the whole cross-section of a nanostructure when its average diameter is comparable to the beam penetration depth (Zarraoa et al. 2019). In our case, we applied $5 \mathrm{kV}$ accelerating voltage for the imaging of the cells. Back scattered electron emission depth at $5 \mathrm{kV}$ increases to $60 \mathrm{~nm}$ for Si. An explanation to why we were not able to detect $\mathrm{N}(0 \%)$ for astrocyte cells in our EDS work would be the EDS measurements are known to become less efficient for lighter atom $(Z<30)$, particularly elements with $Z<10$, minimum detectable mass is usually around $1-2 \%$ under the best conditions. Another explanation of this "zero finding" would be the penetration depth $(\sim 1000 \mathrm{~nm}$ at $5 \mathrm{keV} ; \sim 10-100 \mathrm{~nm}$ at $2 \mathrm{keV}$ ) of X-rays into astrocyte cells were not enough to interact with the components of the cell containing nitrogen at the deeper levels (>1000 nm likely) in the cell since we found the height of the astrocytes $1300 \mathrm{~nm}$ from AFM experiment.

\section{Conclusion}

This paper highlights the differentiation of cancer (GBM) and healthy (astrocyte) cells at molecular level by AFM, SEM-EDS, XPS supported with F-actin immunofluorescence staining and RT-PCR. Combining gene-level molecular data with protein results and morphological reflections were important in seeing the big picture for diseases such as cancer or general cell biology, about which new information is provided every day. F-actin organisation and gene expression results showed up GBM and astrocytes regulates cellular process at molecular level. SEM investigation allowed us to further reveal the filopodial protrusions and their invading structures. XPS gave us a unique opportunity to investigate the cell surface and elucidate detailed cell composition and its micro environmental alterations. XPS survey findings in our work also demonstrated that we were able to distinguish the bond types based on their peak positions. Our results were in consistency with the previous reported data. C, N, S, and O elemental contributions were successfully determined by XPS. By AFM, 3-D topographic images of the cell surfaces were successfully determined. Based on AFM results, lengths and heights of filopodial formations were found to be approximately 5 and $50 \mu \mathrm{m}$ for astrocyte cells which is in agreement with the literature. GBM cells' heights were found to be $1.024 \pm 0.224 \mathrm{~nm}$, which is smaller than the reported by Hsiao et al. (Hsiao et al. 2013). This finding for GBM cells might be attributed to grade levels, high or low, of the cells under 
study or the type of the cell depending on whether it is rat or human. Taken together, our results highlight the role of combinatorial spectroscopic and microscopic techniques as candidate diagnostic tools in cancer and cancer stem cell characterization. However, our findings might not be representative of a more generalized frame since more detailed efforts are required on such specific cells with greater number of cells. Results so far have been promising and could potentially be applied in cancer research, particularly in early diagnosis of cancer.

\section{Declarations}

\section{Conflict of interest}

There are no conflicts to declare.

\section{Acknowledgement}

We thank the Ege University Central Research Testing and Analysis Laboratory Research and Application Center (Izmir/TR) for providing spectroscopic and microscopic infrastructure. This study was supported by Ege University Scientific Research Projects Coordination Unit. Project Number: 18-TIP-013 and 117 S578 TUBITAK (3001) project.

\section{Authors' contributions}

Berrin Ozdil: Data curation, Formal analysis, Methodology, Writing - original draft. Duygu Calik-Kocaturk: Methodology, Writing - original draft. Cisem Altunayar-Unsalan: Methodology, Writing - original draft. Eda Acikgoz: Methodology, Writing - original draft, Writing- Reviewing and Editing. Volkan Gorgulu: Writing Reviewing and Editing. Aysegul Uysal: Supervision, Writing - Reviewing and Editing. Ozan Unsalan: Writing - Reviewing, and Editing, Data analysis. Huseyin Aktug: Conceptualization, Funding acquisition, Methodology, Project administration, Supervision, Writing - Reviewing, and editing. All authors reviewed the manuscript.

\section{References}

Abràmoff MD, Magalhães PJ, Ram SJ (2004) Image processing with imageJ. Biophotonics Int 11:36-41. https://doi.org/10.1201/9781420005615.ax4

Ahimou F, Boonaert CJP, Adriaensen Y, et al (2007) XPS analysis of chemical functions at the surface of Bacillus subtilis. J Colloid Interface Sci 309:49-55.

https://doi.org/https://doi.org/10.1016/j.jcis.2007.01.055

Al-Koussa H, Atat O El, Jaafar L, et al (2020) The Role of Rho GTPases in Motility and Invasion of Glioblastoma Cells. Anal Cell Pathol 2020:9274016. https://doi.org/10.1155/2020/9274016 
Arjonen A, Kaukonen R, Ivaska J (2011) Filopodia and adhesion in cancer cell motility. Cell Adh Migr 5:421-430. https://doi.org/10.4161/cam.5.5.17723

Aspenström P, Ruusala A, Pacholsky D (2007) Taking Rho GTPases to the next level: the cellular functions of atypical Rho GTPases. Exp Cell Res 313:3673-3679.

https://doi.org/10.1016/j.yexcr.2007.07.022

Baharvand H, Matthaei KI (2003) The ultrastructure of mouse embryonic stem cells. Reprod Biomed Online 7:330-335

Beil M, Braxmeier H, Fleischer F, et al (2005) Quantitative analysis of keratin filament networks in scanning electron microscopy images of cancer cells. J Microsc 220:84-95.

https://doi.org/10.1111/j.1365-2818.2005.01505.x

Bergert M, Lembo S, Sharma S, et al (2021) Cell surface mechanics gate embryonic stem cell differentiation. Cell Stem Cell 28:209-216

Boyde A, Weiss RA, Veselý P (1972) Scanning electron microscopy of cells in culture. Exp Cell Res 71:313-324. https://doi.org/https://doi.org/10.1016/0014-4827(72)90299-6

Canetta E, Riches A, Borger E, et al (2014) Discrimination of bladder cancer cells from normal urothelial cells with high specificity and sensitivity: combined application of atomic force microscopy and modulated Raman spectroscopy. Acta Biomater 10:2043-2055.

https://doi.org/10.1016/j.actbio.2013.12.057

Chaboub LS, Deneen B (2012) Developmental origins of astrocyte heterogeneity: the final frontier of CNS development. Dev Neurosci 34:379-388. https://doi.org/10.1159/000343723

Chang C-H, Lee H-H, Lee C-H (2017) Substrate properties modulate cell membrane roughness by way of actin filaments. Sci Rep 7:9068. https://doi.org/10.1038/s41598-017-09618-y

Cheng Q, Wang S (2008) A method for testing the elastic modulus of single cellulose fibrils via atomic force microscopy. Compos Part A Appl Sci Manuf 39:1838-1843.

https://doi.org/https://doi.org/10.1016/j.compositesa.2008.09.007

Comes N, Serrano-Albarrás A, Capera J, et al (2015) Involvement of potassium channels in the progression of cancer to a more malignant phenotype. Biochim Biophys Acta - Biomembr 1848:24772492. https://doi.org/https://doi.org/10.1016/j.bbamem.2014.12.008

D’Agostino DP, Olson JE, Dean JB (2009) Acute hyperoxia increases lipid peroxidation and induces plasma membrane blebbing in human U87 glioblastoma cells. Neuroscience 159:1011-1022. https://doi.org/10.1016/j.neuroscience.2009.01.062

Fleming BN (2014) MICROSCOPES. Nature 575:91 
Franchi M, Piperigkou Z, Riti E, et al (2020) Long filopodia and tunneling nanotubes define new phenotypes of breast cancer cells in 3D cultures. Matrix Biol Plus 6-7:100026.

https://doi.org/https://doi.org/10.1016/j.mbplus.2020.100026

Grauzam S, Brock AM, Holmes CO, et al (2018) NEDD9 stimulated MMP9 secretion is required for invadopodia formation in oral squamous cell carcinoma. Oncotarget 9:25503-25516.

https://doi.org/10.18632/oncotarget.25347

Guo Q, Xia Y, Sandig M, Yang J (2012) Characterization of cell elasticity correlated with cell morphology by atomic force microscope. J Biomech 45:304-309.

https://doi.org/https://doi.org/10.1016/j.jbiomech.2011.10.031

Guttenplan KA, Liddelow SA (2018) Astrocytes and microglia: Models and tools. J Exp Med 216:71-83. https://doi.org/10.1084/jem.20180200

Hohmann T, Dehghani F (2019) The Cytoskeleton-A Complex Interacting Meshwork. Cells 8

Hol EM, Pekny M (2015) Glial fibrillary acidic protein (GFAP) and the astrocyte intermediate filament system in diseases of the central nervous system. Curr Opin Cell Biol 32:121-130. https://doi.org/10.1016/j.ceb.2015.02.004

Hou Y, Xie W, Yu L, et al (2020) Surface Roughness Gradients Reveal Topography-Specific Mechanosensitive Responses in Human Mesenchymal Stem Cells. Small 16:1905422. https://doi.org/10.1002/smll.201905422

Hsiao WW, Liao H-S, Lin H-H, et al (2013) Biophysical analysis of astrocytes apoptosis triggered by larval E/S antigen from cerebral toxocarosis-causing pathogen Toxocara canis. Anal Sci 29:885-892. https://doi.org/10.2116/analsci.29.885

Hu C, Zhou H, Liu Y, et al (2019) ROCK1 promotes migration and invasion of non-small-cell lung cancer cells through the PTEN/PI3K/FAK pathway. Int J Oncol 55:833-844.

https://doi.org/10.3892/ijo.2019.4864

Kaul-Ghanekar R, Singh S, Mamgain H, et al (2009) Tumor suppressor protein SMAR1 modulates the roughness of cell surface: combined AFM and SEM study. BMC Cancer 9:350.

https://doi.org/10.1186/1471-2407-9-350

Kim E (2009) Postsynaptic Development: Neuronal Molecular Scaffolds. In: Squire LRBT-E of N (ed). Academic Press, Oxford, pp 817-824

Lam WA, Rosenbluth MJ, Fletcher DA (2007) Chemotherapy exposure increases leukemia cell stiffness. Blood 109:3505-3508. https://doi.org/10.1182/blood-2006-08-043570 
Lara-Velazquez M, Al-Kharboosh R, Jeanneret S, et al (2017) Advances in Brain Tumor Surgery for Glioblastoma in Adults. Brain Sci 7:. https://doi.org/10.3390/brainsci7120166

Lee CG, Da Silva CA, Dela Cruz CS, et al (2011) Role of chitin and chitinase/chitinase-like proteins in inflammation, tissue remodeling, and injury. Annu Rev Physiol 73:479-501.

https://doi.org/10.1146/annurev-physiol-012110-142250

Lekka M, Laidler P, Gil D, et al (1999) Elasticity of normal and cancerous human bladder cells studied by scanning force microscopy. Eur Biophys J 28:312-316. https://doi.org/10.1007/s002490050213

Li M, Xi N, Wang Y, Liu L (2021) Atomic force microscopy for revealing micro/nanoscale mechanics in tumor metastasis: from single cells to microenvironmental cues. Acta Pharmacol Sin 42:323-339. https://doi.org/10.1038/s41401-020-0494-3

Li QS, Lee GYH, Ong CN, Lim CT (2008) AFM indentation study of breast cancer cells. Biochem Biophys Res Commun 374:609-613. https://doi.org/10.1016/j.bbrc.2008.07.078

Liliom H, Lajer P, Bérces Z, et al (2019) Comparing the effects of uncoated nanostructured surfaces on primary neurons and astrocytes. J Biomed Mater Res Part A 107:2350-2359.

https://doi.org/10.1002/jbm.a.36743

Lin DC, Dimitriadis EK, Horkay F (2007) Robust strategies for automated AFM force curve analysis-I. Nonadhesive indentation of soft, inhomogeneous materials. J Biomech Eng 129:430-440. https://doi.org/10.1115/1.2720924

Louis DN, Perry A, Reifenberger G, et al (2016) The 2016 World Health Organization Classification of Tumors of the Central Nervous System: a summary. Acta Neuropathol. 131:803-820

McArthur SL, Mishra G, Easton CD (2014a) Applications of XPS in biology and biointerface analysis. In: Surface Analysis and Techniques in Biology. Springer International Publishing, pp 9-36

McArthur SL, Mishra G, Easton CD (2014b) Applications of XPS in Biology and Biointerface Analysis BT - Surface Analysis and Techniques in Biology. In: Smentkowski VS (ed). Springer International Publishing, Cham, pp 9-36

McEwen GD, Wu Y, Tang M, et al (2013) Subcellular spectroscopic markers, topography and nanomechanics of human lung cancer and breast cancer cells examined by combined confocal Raman microspectroscopy and atomic force microscopy. Analyst 138:787-797.

https://doi.org/10.1039/c2an36359c

Morgan AJ (1985) X-Ray Microanalysis in Electron Microscopy for Biologists. Microscopy Handbooks 05. Oxford University Press. 1985 
Mullen CA, Vaughan TJ, Voisin MC, et al (2014) Cell morphology and focal adhesion location alters internal cell stress. J R Soc Interface 11:20140885

Murali A, Rajalingam K (2014) Small Rho GTPases in the control of cell shape and mobility. Cell Mol Life Sci 71:1703-1721. https://doi.org/10.1007/s00018-013-1519-6

Oberheim NA, Takano T, Han X, et al (2009) Uniquely hominid features of adult human astrocytes. J Neurosci 29:3276-3287. https://doi.org/10.1523/JNEUROSCl.4707-08.2009

Oberleithner H, Brinckmann E, Schwab A, Krohne G (1994) Imaging nuclear pores of aldosterone-sensitive kidney cells by atomic force microscopy. Proc Natl Acad Sci U S A 91:9784-9788. https://doi.org/10.1073/pnas.91.21.9784

Okura H, Golbourn BJ, Shahzad U, et al (2016) A role for activated Cdc42 in glioblastoma multiforme invasion. Oncotarget 7:56958-56975. https://doi.org/10.18632/oncotarget.10925

Oltulu F, Kocaturk DC, Adali Y, et al (2019) Autophagy and mTOR pathways in mouse embryonic stem cell, lung cancer and somatic fibroblast cell lines. J Cell Biochem 120:18066-18076.

https://doi.org/10.1002/jcb.29110

Ostrom QT, Cioffi G, Gittleman H, et al (2019) CBTRUS Statistical Report: Primary Brain and Other Central Nervous System Tumors Diagnosed in the United States in 2012-2016. Neuro Oncol 21:v1-v100. https://doi.org/10.1093/neuonc/noz150

Ozdil B, Calik-Kocaturk D, Altunayar-Unsalan C, et al (2021) Spectroscopic and microscopic comparisons of cell topology and chemistry analysis of mouse embryonic stem cell, somatic cell and cancer cell. Acta Histochem 123:151763. https://doi.org/https://doi.org/10.1016/j.acthis.2021.151763

Palumbo P, Lombardi F, Augello FR, et al (2020) Biological effects of selective COX-2 inhibitor NS398 on human glioblastoma cell lines. Cancer Cell Int 20:1-17

Polyakov P, Soussen C, Duan J, et al (2011) Automated force volume image processing for biological samples. PLoS One 6:e18887. https://doi.org/10.1371/journal.pone.0018887

Radisky DC, Levy DD, Littlepage LE, et al (2005) Rac1b and reactive oxygen species mediate MMP-3induced EMT and genomic instability. Nature 436:123-127. https://doi.org/10.1038/nature03688

Rasband WS ImageJ. In: U. S. Natl. Institutes Heal. Bethesda, Maryland, USA. https://imagej.nih.gov/ij/

Recek N, Cheng X, Keidar M, et al (2015) Effect of Cold Plasma on Glial Cell Morphology Studied by Atomic Force Microscopy. PLoS One 10:e0119111

Rouxhet P, Mozes N, DENGIS P, et al (1994) Application of X-ray photoelectron spectroscopy to microorganisms. Colloids Surfaces B Biointerfaces, 2 347*369 
Schneider CA, Rasband WS, Eliceiri KW (2012) NIH Image to ImageJ: 25 years of image analysis. Nat Methods 9:671-675. https://doi.org/10.1038/nmeth.2089

Scimeca M, Bischetti S, Lamsira HK, et al (2018) Energy Dispersive X-ray (EDX) microanalysis: A powerful tool in biomedical research and diagnosis. Eur J Histochem 62:2841.

https://doi.org/10.4081/ejh.2018.2841

Sirghi L, Bretagnol F, Mornet S, et al (2009) Atomic force microscopy characterization of the chemical contrast of nanoscale patterns fabricated by electron beam lithography on polyethylene glycol oxide thin films. Ultramicroscopy 109:222-229. https://doi.org/10.1016/j.ultramic.2008.10.022

Sirghi L, Ponti J, Broggi F, Rossi F (2008) Probing elasticity and adhesion of live cells by atomic force microscopy indentation. Eur Biophys J 37:935-945. https://doi.org/10.1007/s00249-008-0311-2

Skallberg A, Brommesson C, Uvdal K (2017) Imaging XPS and photoemission electron microscopy; surface chemical mapping and blood cell visualization. Biointerphases 12:02C408.

https://doi.org/10.1116/1.4982644

Smith JR, Maherally Z, Higgins SC, et al (2016) AFM Observation of Heightened Cell Periphery of HighGrade Glioblastoma Cell Lines. Bionanoscience 6:47-53. https://doi.org/10.1007/s12668-015-0188-3

Smith JR, Tsibouklis J, Nevell TG, Breakspear S (2013) AFM friction and adhesion mapping of the substructures of human hair cuticles. Appl Surf Sci 285:638-644.

https://doi.org/https://doi.org/10.1016/j.apsusc.2013.08.104

Sofroniew M V, Vinters H V (2010) Astrocytes: biology and pathology. Acta Neuropathol 119:7-35. https://doi.org/10.1007/s00401-009-0619-8

Steffen J, Koehler CM (2018) ER - mitochondria contacts: Actin dynamics at the ER control mitochondrial fission via calcium release. Rockefeller Univ Press J Cell Biol J 3-5.

https://doi.org/10.1083/jcb.201711075

Suresh S (2007a) Nanomedicine: elastic clues in cancer detection. Nat. Nanotechnol. 2:748-749

Suresh S (2007b) Biomechanics and biophysics of cancer cells. Acta Biomater 3:413-438. https://doi.org/10.1016/j.actbio.2007.04.002

Tang WJ, Fernandez J, Sohn JJ, Amemiya CT (2015) Chitin is endogenously produced in vertebrates. Curr Biol 25:897-900. https://doi.org/10.1016/j.cub.2015.01.058

Tiryaki VM, Ayres VM, Khan AA, et al (2012) Nanofibrillar scaffolds induce preferential activation of Rho GTPases in cerebral cortical astrocytes. Int J Nanomedicine 7:3891-3905.

https://doi.org/10.2147/IJN.S32681 
Tseliou M, Al-Qahtani A, Alarifi S, et al (2016) The Role of RhoA, RhoB and RhoC GTPases in Cell Morphology, Proliferation and Migration in Human Cytomegalovirus (HCMV) Infected Glioblastoma Cells. Cell Physiol Biochem 38:94-109. https://doi.org/10.1159/000438612

Urbańska K, Sokołowska J, Szmidt M, Sysa P (2014) Glioblastoma multiforme - an overview. Contemp Oncol 18:307-312. https://doi.org/10.5114/wo.2014.40559

Valdes-Rives SA, Casique-Aguirre D, German-Castelan L, et al (2017) Apoptotic Signaling Pathways in Glioblastoma and Therapeutic Implications. Biomed Res Int 2017:7403747. https://doi.org/10.1155/2017/7403747

Velásquez C, Mansouri S, Gutiérrez O, et al (2019) Hypoxia Can Induce Migration of Glioblastoma Cells Through a Methylation-Dependent Control of ODZ1 Gene Expression .Front. Oncol. 9:1036

Wang Y, Xu C, Jiang N, et al (2016) Quantitative analysis of the cell-surface roughness and viscoelasticity for breast cancer cells discrimination using atomic force microscopy. Scanning 38:558-563.

https://doi.org/10.1002/sca.21300

Weissmüller G, Garcia-Abreu J, Mascarello Bisch P, et al (2000) Glial cells with differential neurite growthmodulating properties probed by atomic force microscopy. Neurosci Res 38:217-220. https://doi.org/10.1016/S0168-0102(00)00159-0

Yang C, Rahimpour S, Yu ACH, et al (2013) Regulation and dysregulation of astrocyte activation and implications in tumor formation. Cell Mol Life Sci 70:4201-4211. https://doi.org/10.1007/s00018-0131274-8

Yang F-C, Atkinson SJ, Gu Y, et al (2001) Rac and Cdc42 GTPases control hematopoietic stem cell shape, adhesion, migration, and mobilization. Proc Natl Acad Sci 98:5614 LP - 5618.

https://doi.org/10.1073/pnas.101546898

Zarraoa L, González MU, Paulo ÁS (2019) Imaging low-dimensional nanostructures by very low voltage scanning electron microscopy: ultra-shallow topography and depth-tunable material contrast. Sci Rep 9:16263. https://doi.org/10.1038/s41598-019-52690-9

Zhou B, Zuo Y-X, Jiang R-T (2019) Astrocyte morphology: Diversity, plasticity, and role in neurological diseases. CNS Neurosci Ther 25:665-673. https://doi.org/10.1111/cns.13123

Zhou D, Jiang X, Xu R, et al (2008) Assessing the cytoskeletal system and its elements in C6 glioma cells and astrocytes by atomic force microscopy. Cell Mol Neurobiol 28:895-905.

https://doi.org/10.1007/s10571-008-9267-0

\section{Tables}


Table 1: The average ct (cycle threshold) values of GBM and astrocytes and fold change values of GBM relative to astrocytes. ACTB and GAPDH genes used for normalization. Blue and red values indicate up and down gene expression respectively.

\begin{tabular}{c|ccrc}
\multicolumn{2}{c}{ AVG ct } & FOLD CHANGE & \\
\hline & GBM & ASTROCYTE & GBM/ASTROCYTE & \\
CDC42 & 28.53 & 24.17 & 35.6707 & UP \\
MMP9 & 32.20 & 38.20 & 46879.4059 & UP \\
MMP2 & 33.35 & 31.99 & 285.3654 & UP \\
ARPC2 & 39.80 & 29.07 & 0.4313 & DOWN \\
RHOA & 25.93 & 22.49 & 67.4930 & UP \\
GFAP & 32.30 & 35.07 & 4996.3771 & UP \\
ROCK1 & 34.02 & 24.76 & 1.1947 & UP \\
ACTB & 38.70 & 22.46 & 0.0095 & DOWN \\
GAPDH & 25.09 & 20.61 & 32.8237 & UP
\end{tabular}

Table 2: Root mean square roughness $\left(R_{q}\right)$, average roughness $\left(R_{a}\right)$ and maximum height $\left(R_{\max }\right)$ data of cancer (GBM), healthy (astrocyte) cells. Data are given as mean values \pm standard deviations.

\begin{tabular}{lccc} 
Cell line & $\mathbf{R}_{\mathrm{q}}(\mathrm{nm})$ & $\mathbf{R}_{\mathrm{a}}(\mathrm{nm})$ & $\mathbf{R}_{\max }(\mathrm{nm})$ \\
\hline GBM & $106.19 \pm 30.53$ & $49.17 \pm 18.12$ & $1024.70 \pm 224.39$ \\
Astrocyte & $113.30 \pm 44.02$ & $46.77 \pm 21.31$ & $1322.67 \pm 381.78$ \\
\hline
\end{tabular}

\section{Figures}
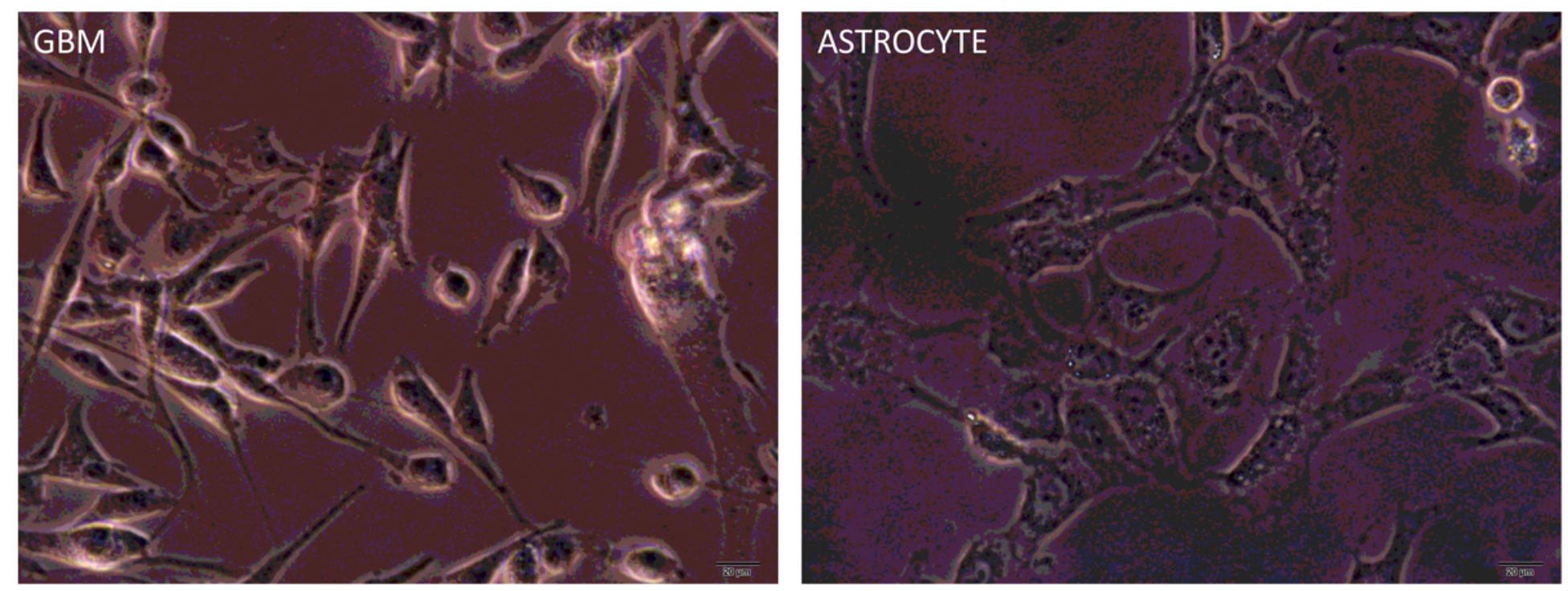

Figure 1 
Phase-contrast images of GBM and astrocyte cells. GBM and astrocyte cells were similar due to their protrusions and the size of cell body, however astrocytes were more spread to the surface and the height of the cells was lower.

\section{A) GBM}
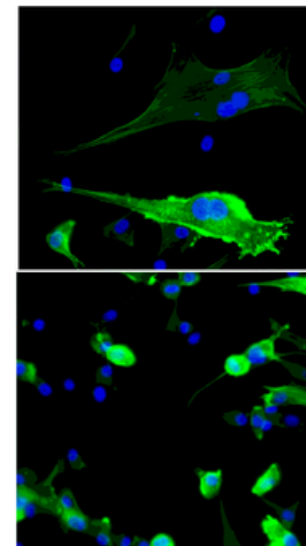

F-ACTIN DAPI

\section{C) ACTIN INTENSITY}

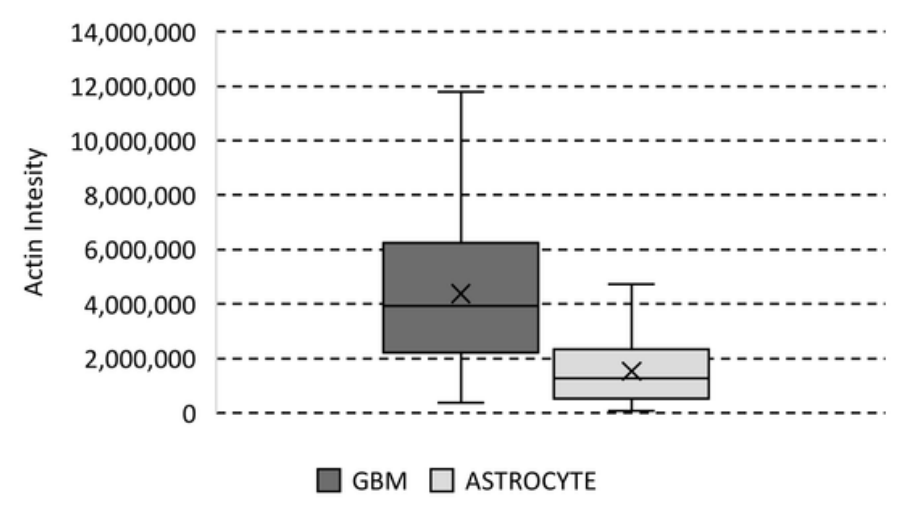

\section{B) ASTROCYTE}

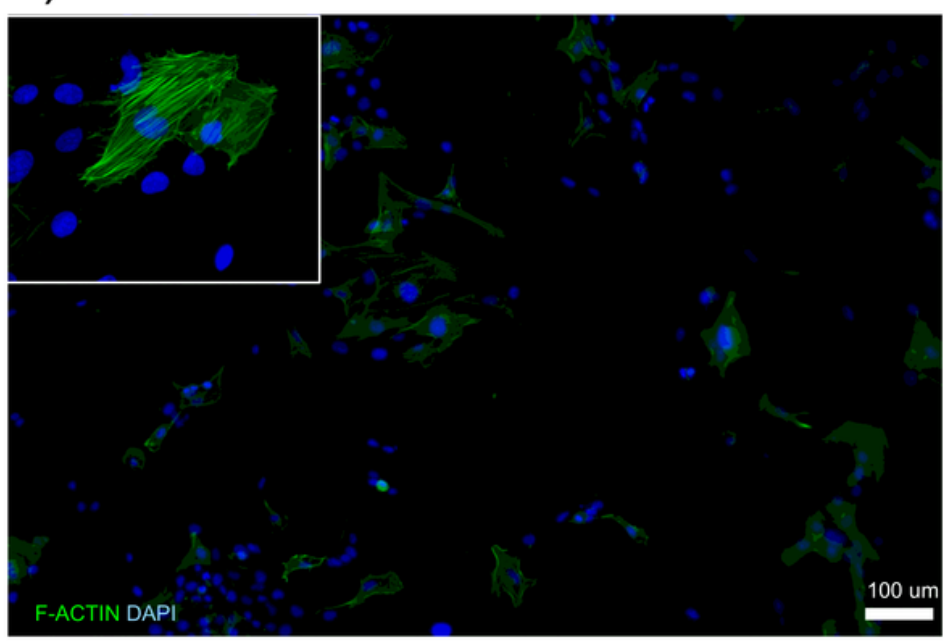

\section{D) ASPECT RATIO}

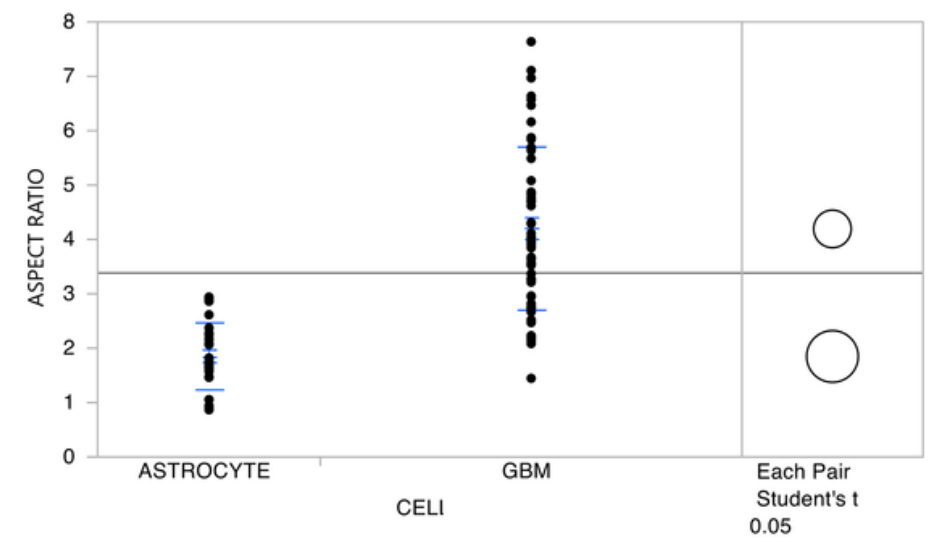

Figure 2

Cytoskeletal structure. The actin staining of (A) GBM and (B) astrocyte cells showed different organization of actin molecules. C) The protein intensity of F-actin was compared in astrocytes and GBM. D) The aspect ratio of cells was computed from actin staining indicates the morphological regulation of these cell lines. 
A

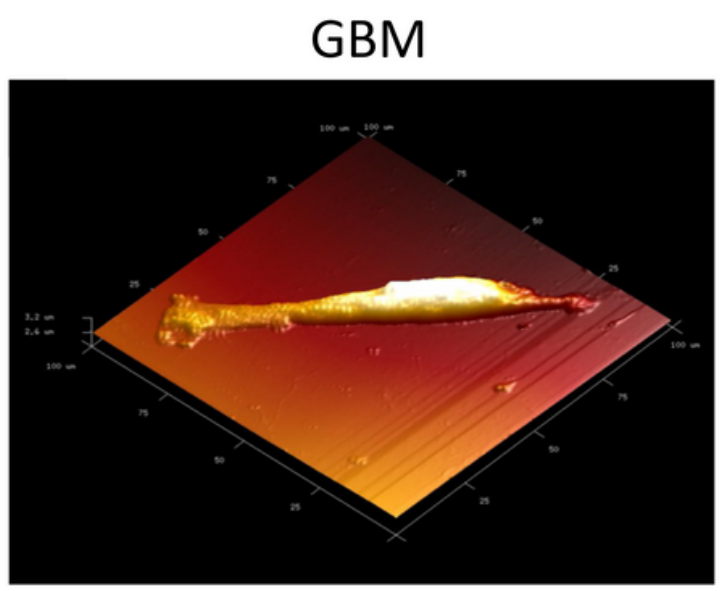

B

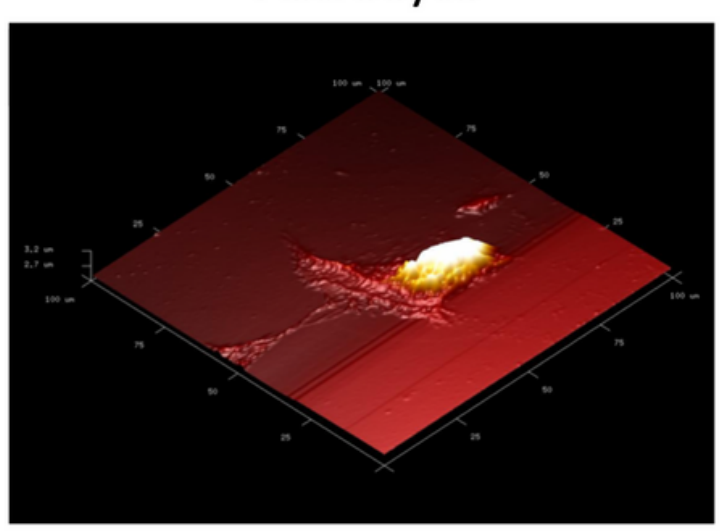

C

AFM-Rq values

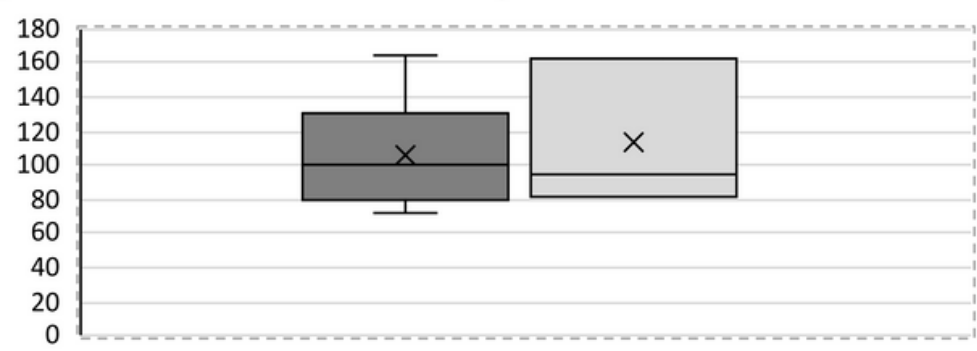

$\square$ GBM $\square$ Astrocyte

AFM-Ra values

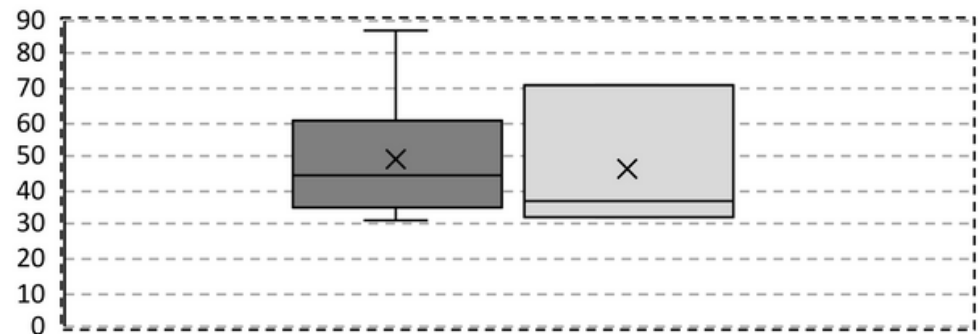

$\square$ GBM $\square$ Astrocyte

E

AFM-Rmax values

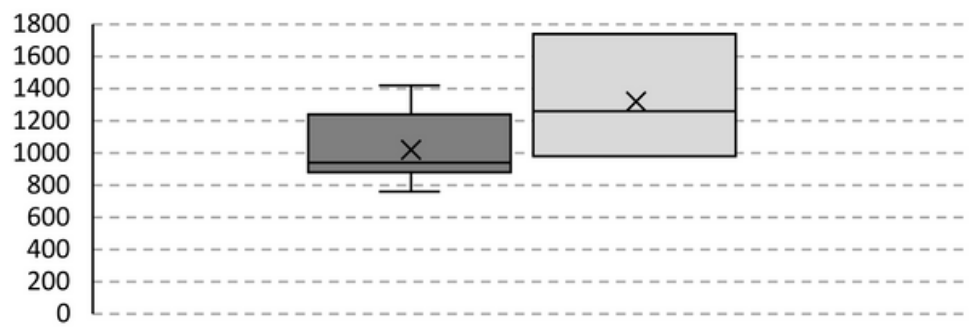

$\square$ GBM $\square$ Astrocyte

\section{Figure 3}

AFM images of A) GBM and B) astrocyte cells together with C) root mean square roughness (Rq), D) average roughness $(\mathrm{Ra})$ and $\mathrm{E})$ maximum height (Rmax) analyses. 


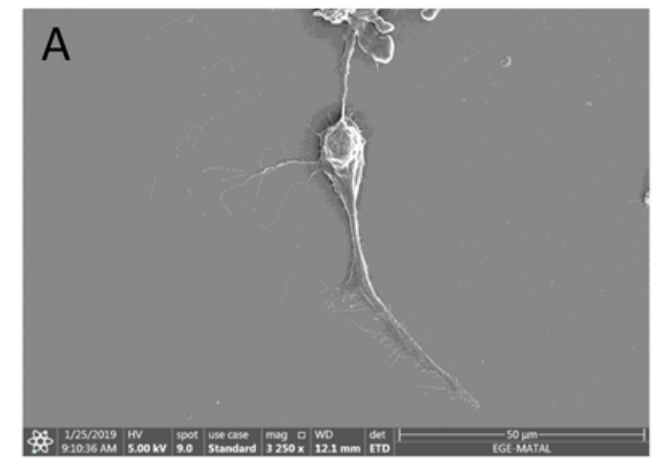

C
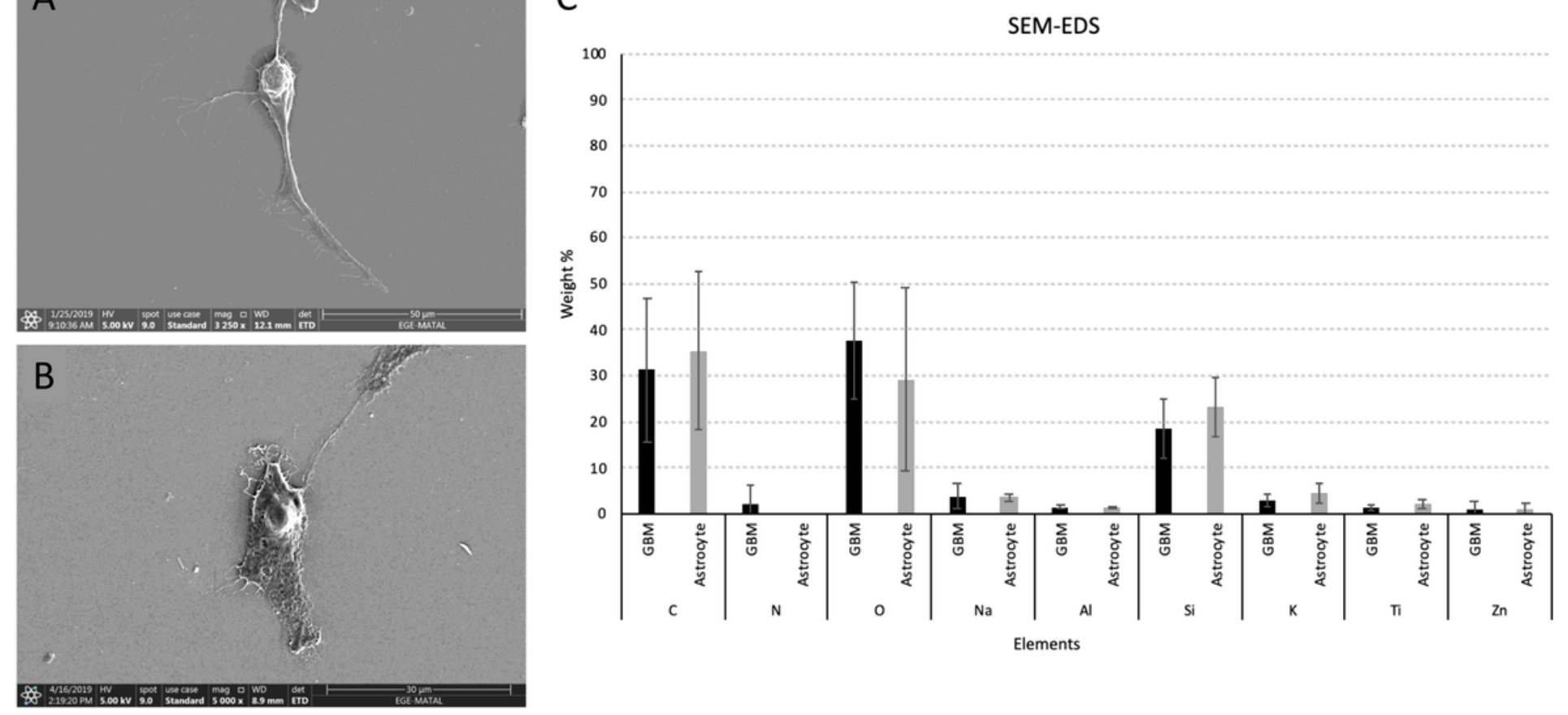

Figure 4

SEM images of the GBM (A) and astrocyte (B). Comparative EDS results of these cells (C). 
A
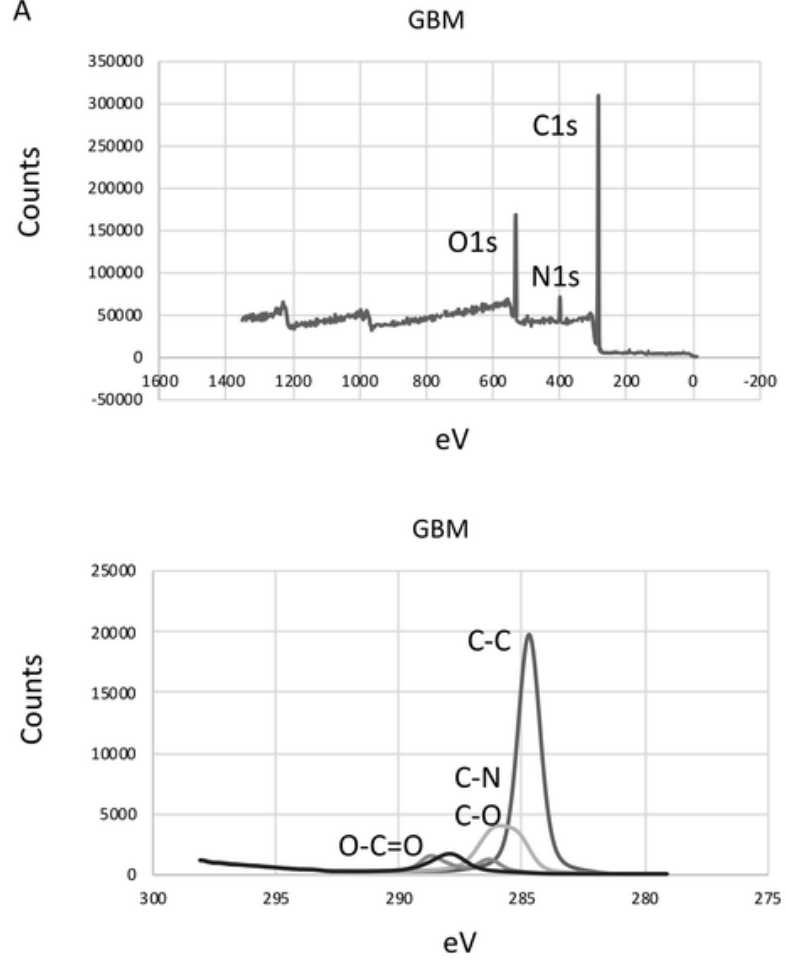

GBM

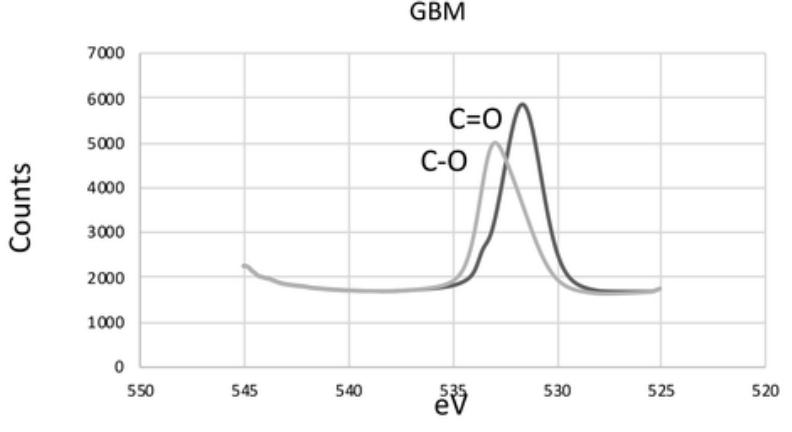

GBM

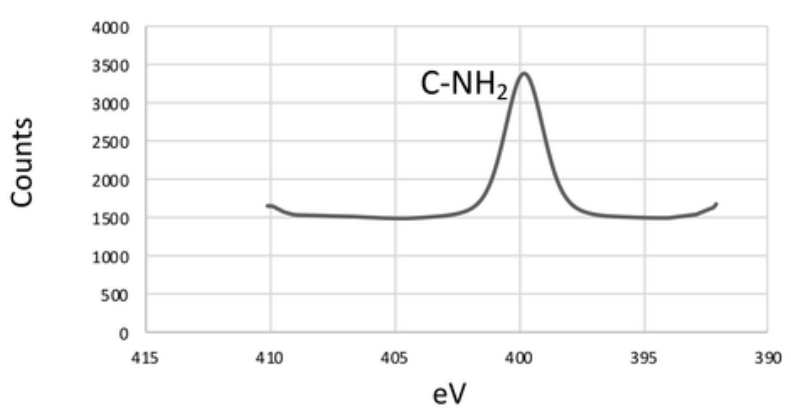

B

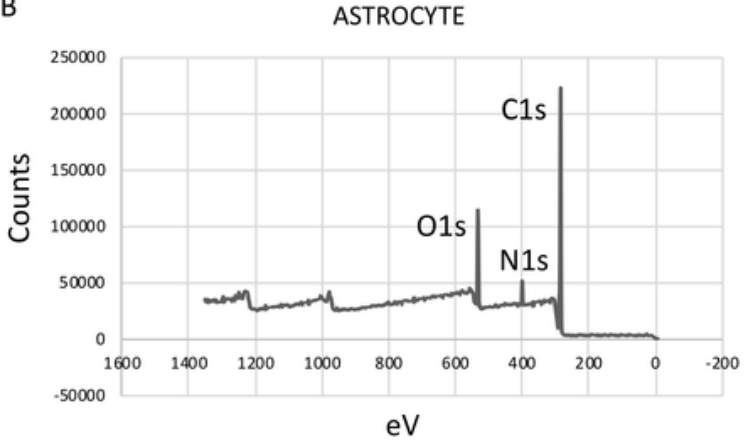

ASTROCYTE

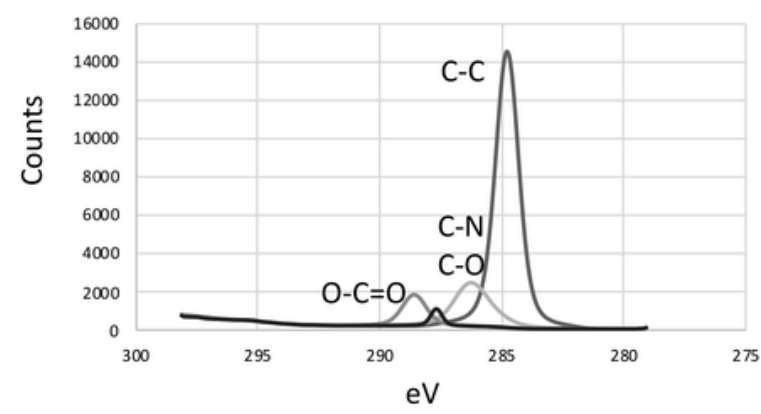

ASTROCYTE

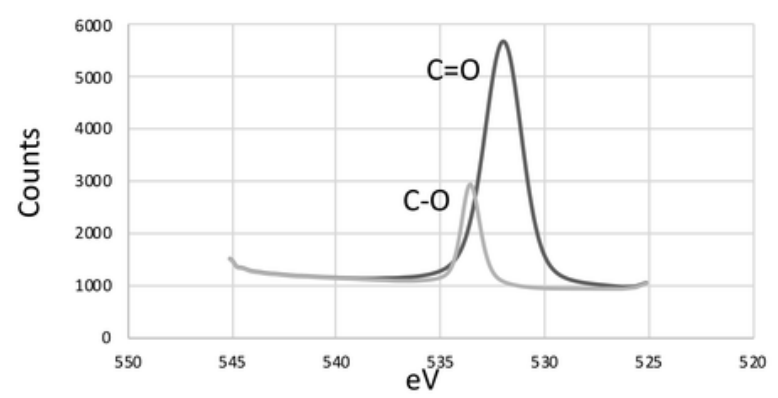

ASTROCYTE

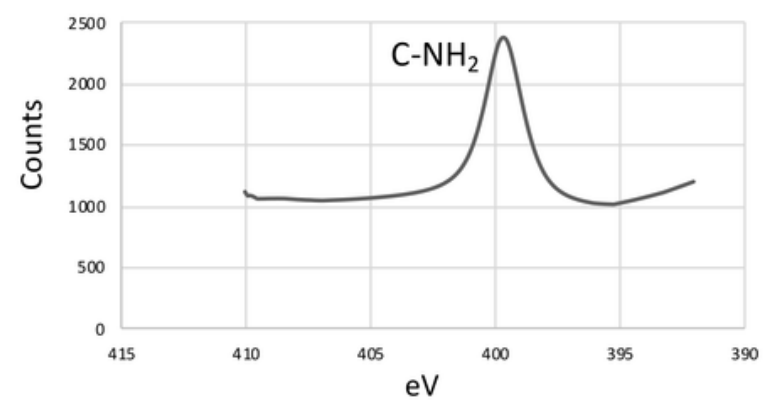

\section{Figure 5}

Peak binding energies of $C, N$ and $O$ elements and their bonding types for GBM $(A)$ and astrocytes (B). 


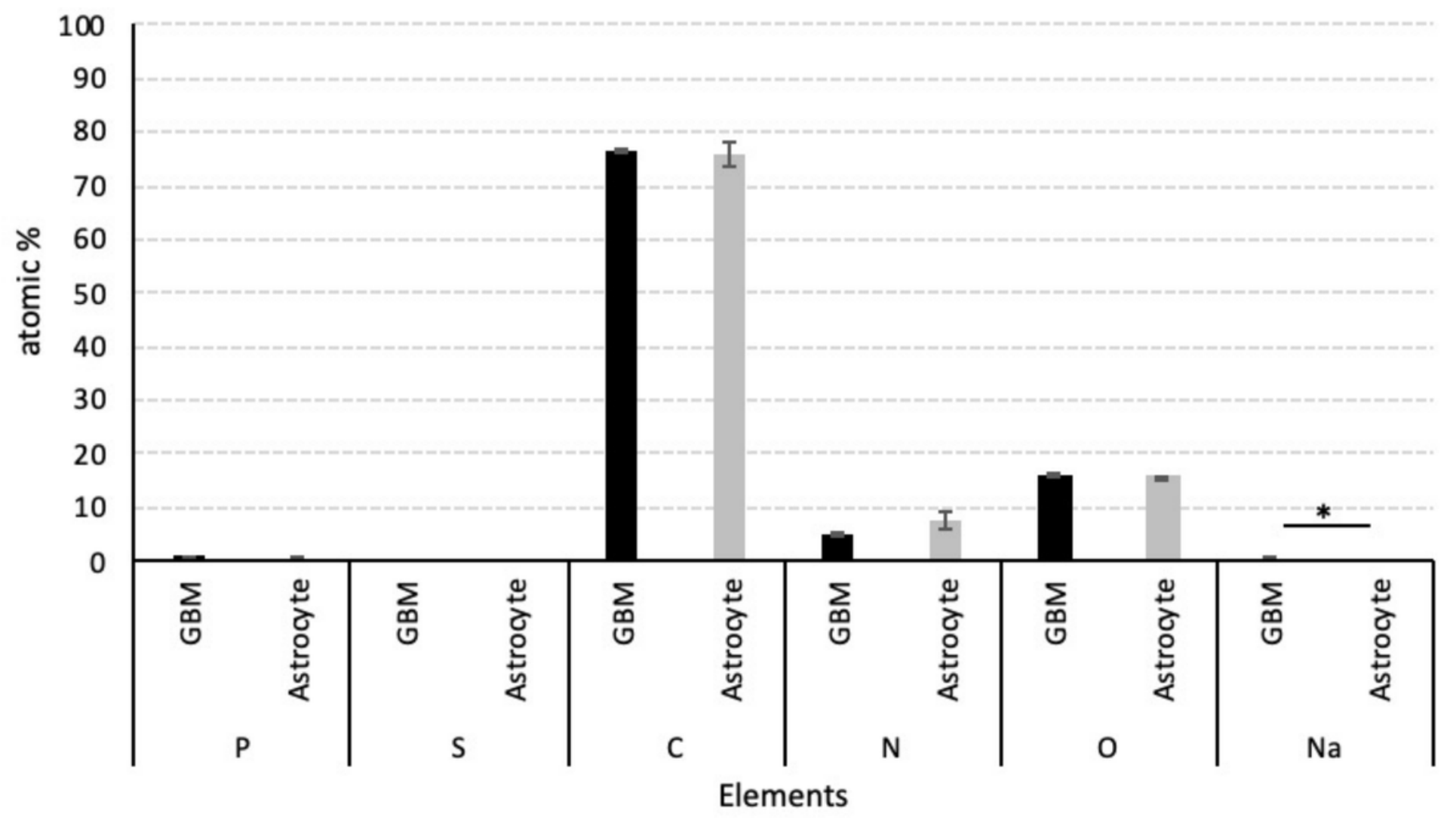

Figure 6

Observed elements vs atomic\% for GBM and astrocytes by XPS.

\section{Supplementary Files}

This is a list of supplementary files associated with this preprint. Click to download.

- grapabs.tif

- SuppTablesv2.docx

- suppfig1.docx 